\section{BRAZIULIAN JOURNAL}

OF MEDICAL AND BIOLOGICAL RESFARCH

www.bjournal.com.br
ISSN 0100-879X

Volume 44 (1) 1-83 January 2011

CLINICAL INVESTIGATION

Braz J Med Biol Res, January 2011, Volume 44(1) 46-52

doi: 10.1590/S0100-879X2010007500150

Three-year follow-up study of respiratory and systemic manifestations of chronic obstructive pulmonary disease

R. Ferrari, S.E. Tanni, M.M. Faganello, L.M.O. Caram, P.A. Lucheta and I. Godoy

The Brazilian Journal of Medical and Biological Research is partially financed by

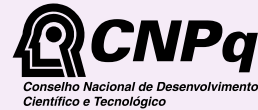

Ministério

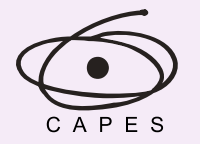

Ministério da Educação

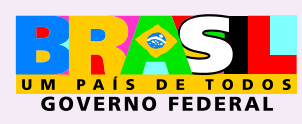

DFAPESP

Institutional Sponsors
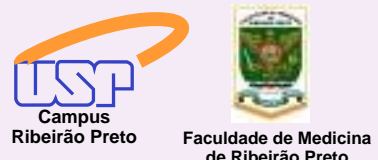

$\oplus$ SHIMADZU

GE Healthcare
Hotsite of proteomics metabolomics developped by: 


\title{
Three-year follow-up study of respiratory and systemic manifestations of chronic obstructive pulmonary disease
}

\author{
R. Ferrari ${ }^{1}$, S.E. Tanni ${ }^{1}$, M.M. Faganello ${ }^{2}$, L.M.O. Caram ${ }^{1}$, \\ P.A. Lucheta ${ }^{1}$ and I. Godoy ${ }^{1}$ \\ ${ }^{1}$ Disciplina de Pneumologia, Departamento de Clínica Médica, Faculdade de Medicina de Botucatu, \\ Universidade Estadual Paulista, Botucatu, SP, Brasil \\ ${ }^{2}$ Departamento de Fisioterapia, UNISALESIANO, Lins, SP, Brasil
}

\begin{abstract}
Few studies show patient outcomes over time in chronic obstructive pulmonary disease (COPD). In the present study, we monitored forced expiratory volume in the first second $\left(\mathrm{FEV}_{1}\right)$ and other manifestations of the disease over 3 years in $133 \mathrm{COPD}$ patients $\left(69 \%\right.$ males, age $=65 \pm 9$ years, $\left.\mathrm{FEV}_{1}=59 \pm 25 \%\right)$ evaluated at baseline. During follow-up, 15 patients $(11 \%)$ died and $23(17 \%)$ dropped out. Measurements for 95 (72\%) COPD patients alive after 3 years were analyzed. FEV 1 , body mass index (BMI), 6-min walking distance (6MWD), Medical Research Council scale (MRC), Saint George's Respiratory Questionnaire (SGRQ), Charlson Comorbidity index, and BODE index were obtained at baseline and after 3 years. At baseline, 17 patients (18\%) presented mild, $39 \%$ moderate, $19 \%$ severe, and $24 \%$ very severe COPD. Predicted FEV $1 \%$ and BMI did not change over the period $(P>0.05)$. FEV 1 in liters [1.25 (0.96-1.72) vs 1.26 (0.88-1.60) L; $P<0.001], 6 M W D(438 \pm 86$ vs $412 \pm 100 \mathrm{~m}$; $\mathrm{P}<0.001)$, MRC [1 (1-2) vs 2 (1-3); $\mathrm{P}=0.002$ ], Charlson index [3 (3-4) vs 4 (3-5); $\mathrm{P}=0.009$ ], BODE index (2.2 \pm 1.8 vs 2.6 $\pm 2.3 ; \mathrm{P}=0.008)$, and total SGRQ (42 \pm 19 vs $44 \pm 19 \%$; $P=0.041)$ worsened after 3 years compared to baseline measurements. These data show that COPD patients deteriorated during the 3-year follow-up despite the fact that they had only minor modifications in airway obstruction and body composition. They support the need for comprehensive patient assessment to better identify disease progression.
\end{abstract}

Key words: Chronic obstructive pulmonary disease; Markers of disease severity; Quality of life; Exercise capacity; BODE index

\section{Introduction}

Chronic obstructive pulmonary disease (COPD) is characterized by chronic airflow limitation and a range of pathological changes in the lungs, some significant extrapulmonary effects, and important comorbidities, which may contribute to the severity of the disease (1). The recognition and quantitation of disease manifestations provide a more comprehensive assessment of disease severity and are important for the determination of prognosis (1). However, in comparison to physiological changes in pulmonary function, the progression of other patient outcomes over time has been examined less frequently.

The traditional pulmonary function test assessed by the forced expiratory volume in the first second $\left(F E V_{1}\right)$ is known to correlate poorly with dyspnea (2), health status (3), and exercise intolerance (4). Furthermore, longitudinal studies have shown that changes in the dyspnea sensation occur independently of alterations in airway obstruction assessed by FEV $1(5,6)$. Oga et al. (7) showed deterioration of health status over 5 years, with changes being only weakly correlated with changes in $\mathrm{FEV}_{1}(7)$. Another longitudinal study showed that exercise tolerance declined over time without correlation with the rate of decline in $\mathrm{FEV}_{1}$ (8).

These data show that follow-up surveys are important for capturing the overall deterioration during COPD. The present study is the first designed to evaluate the follow-up of respiratory and systemic markers of disease in Brazilian COPD patients in order to determine whether the follow-up of the disease presents the same pattern as described by

Correspondence: R. Ferrari, Departamento de Clínica Médica, Faculdade de Medicina de Botucatu, UNESP, Distrito de Rubião Junior, s/n, 18618-970 Botucatu, SP, Brasil. Fax: +55-14-3882-2238. E-mail: renataferrarifisio@gmail.com

Received August 26, 2010. Accepted December 8, 2010. Available online December 24, 2010. Published January $17,2011$. 
previous investigators in international studies.

\section{Patients and Methods}

\section{Patients}

A total of 133 consecutive COPD patients with mild to very severe disease were recruited from the outpatient clinic of Hospital Universitário, Faculdade de Medicina de Botucatu. Disease severity was categorized according to the Brazilian Thoracic Society (BTS) and GOLD stages taking into consideration the values of $\mathrm{FEV}_{1}$ (\% predicted) and arterial blood gases (Table 1) (1,9).

Major inclusion criteria were clinical diagnosis of COPD according to the 2006 GOLD report and BTS $(1,9)$ : age $\geq 40$ years, smoking history of $\geq 10$ pack-years, and a post-bronchodilator $\mathrm{FEV}_{1} /$ forced expiratory vital capacity (FVC) ratio $<70 \%$. The following factors were grounds for exclusion: a history of asthma and/or $\mathrm{FEV}_{1}$ increase $>12 \%$ or a 200-mL post-bronchodilator test, associated restrictive disorders (tuberculosis sequelae, interstitial fibrosis), other clinically significant concomitant respiratory diseases (sleep apnea/hypopnea syndrome, lung cancer), noncompliance with treatment, myocardial infarction within the preceding 4 months, and unstable angina or congestive heart failure (New York Heart Association class III or IV). Patients not considered to be clinically stable (i.e., with disease exacerbation, hospital admissions in the preceding 6 weeks or changes in medication dose or frequency) were also excluded at baseline. All patients were optimized in terms of standard medical therapy according to GOLD and BTS guidelines $(1,9)$. Patients with chronic hypoxemia were receiving a stable oxygen therapy dose over a period of 6 months before enrollment in the study.

All patients were evaluated at baseline and attended at the clinics every 6 months for 3 years or until death. In addition, patients or their families were contacted by telephone every 3 months to determine the occurrence of exacerbations, and to inquire about the cause of death when the patient died. Data were confirmed during visits at the clinics and by reviewing medical records. Basic causes of death were reviewed on death certificates when available. Evaluation after 3 years was similar to the initial assessment, and was performed when patients were considered to be clinically stable. Smoking history was obtained by patient interview using standardized instruments at baseline and smoking cessation was checked during patients' contacts. Clinical assessment, collection of arterial blood gases (in patients with severe and very severe COPD) and spirometry (pre- and post-bronchodilator) were performed on the first day, and nutritional status, the 6-min walking distance (6MWD), health status and dyspnea perception were assessed on an additional day. All procedures were approved by the Research Ethics Committee of Hospital Universitário, Faculdade de Medicina de Botucatu, and all patients gave written informed consent to participate in the study.

\section{Pulmonary function, pulse oximetry, and arterial blood gas analysis}

Spirometry was performed using a KOKO Spirometer before and $15 \mathrm{~min}$ after the inhalation of $400 \mu \mathrm{g}$ salbutamol (Ferrari KOKO, USA), according to criteria of the American Thoracic Society (10). FEV 1 values are reported in liters as percentages of FVC and of the reference values (11). Pulse oximetry $\left(\mathrm{SpO}_{2}\right)$ was assessed using an Onyx oximeter (Model 9500 Oximeter; Nonin Medical Inc., USA) while patients were breathing room air. Blood gas measurements were performed only to characterize GOLD III and IV patients. Blood was drawn from the brachial artery when patients were at rest and breathing room air. Partial pressure of oxygen $\left(\mathrm{PaO}_{2}\right)$ and partial pressure of carbon dioxide $\left(\mathrm{PaCO}_{2}\right)$ were assessed with a blood analyzer (Stat Profile 5 Plus; Nova Biomedical, USA).

\section{Nutritional assessment}

Body weight and height were measured and body mass index $\left[\mathrm{BMl}=\right.$ weight $(\mathrm{kg}) /$ height $\left.(\mathrm{m})^{2}\right]$ was calculated. Body composition was evaluated by bioelectrical impedance (BIA 101A; RJL systems, USA) according to the guidelines of the European Society for Parenteral and Enteral Nutrition (ESPEN) (12). Fat-free mass (FFM, kg) was calculated using a group-specific regression equation developed by Kyle et al. (13). The FFM index (FFMI $=F F M /$ height $\left.^{2}\right)$ was also calculated. Lean body mass depletion was defined as an FFMI $<15 \mathrm{~kg} / \mathrm{m}^{2}$ for women and $<16 \mathrm{~kg} / \mathrm{m}^{2}$ for men (14).

\section{Health status and dyspnea}

A translated version of the Saint George's Respiratory Questionnaire (SGRQ), validated for use in Brazil, was used to evaluate patient health status (15). Clinically significant improvement was defined as a decrease of $\geq 4 \%$

Table 1. Distribution of chronic obstructive pulmonary disease (COPD) patients according to disease severity $(1,9)$.

\begin{tabular}{|c|c|c|c|c|}
\hline Patients & $\begin{array}{l}\text { Patients with mild } \\
\text { COPD }\left(F E V_{1} \geq 80 \%\right)\end{array}$ & $\begin{array}{l}\text { Patients with moderate } \\
\text { COPD }\left(50 \leq \mathrm{FEV}_{1}<80 \%\right)\end{array}$ & $\begin{array}{l}\text { Patients with severe COPD } \\
\quad\left(30 \leq \mathrm{FEV}_{1}<50 \%\right)\end{array}$ & $\begin{array}{c}\text { Patients with very severe COPD } \\
\left(\mathrm{FEV}_{1}<30 \% \text { or } \mathrm{FEV}_{1}<50 \%+\right. \\
\text { chronic respiratory failure })\end{array}$ \\
\hline 133 & 23 & 46 & 23 & 41 \\
\hline
\end{tabular}

Data are reported as number of patients. $\mathrm{FEV}_{1}=$ forced expiratory volume in the first second. 
in total SGRQ score (16). Dyspnea was assessed using a validated Brazilian version of the Medical Research Council (MRC) scale (17).

\section{Exercise tolerance}

The 6MWD was performed according to the guidelines of the American Thoracic Society (18). Patients were instructed to walk, attempting to cover as much ground as possible within $6 \mathrm{~min}$. A research assistant timed the walk, and standardized verbal encouragement was given. Following a rest of at least $30 \mathrm{~min}$, each subject performed a second $6 \mathrm{MWD}$ in the same manner as the first. Patient $\mathrm{SpO}_{2}$ was monitored throughout the test. Patients who were hypoxic at baseline and patients whose $\mathrm{SpO}_{2}$ decreased to $<85 \%$ during the test were given oxygen by a physical therapist who wheeled an oxygen tank in a handcart alongside the patient. Before and after the test, data were obtained for $\mathrm{SpO}_{2}$, heart rate, respiratory rate, dyspnea sensation (Borg scale dyspnea score), and blood pressure. The distance covered is reported in meters. There are two different references to define the minimum clinically significant decline in $6 M W D(19,20)$ : a reduction $\geq 54 \mathrm{~m}$ (19) or $\geq 35 \mathrm{~m}$ (20) from baseline. In this study, we evaluated the 6MWD decline according to both definitions.

\section{BODE index and comorbidity evaluation}

The BMI/airflow obstruction/dyspnea/exercise capacity (BODE) index was calculated using the model described by Celli et al. (21). BODE scores were categorized as class 1 (score: 0 to 2 ), class 2 (score: 3 to 4 ), class 3 (score: 5 to 6 ), or class 4 (score: 7 to 10) (21). Each patient's BODE was classified as being decreased ( $\geq 1$ point), stable, or increased ( $\geq 1$ point) based on its absolute change from baseline, as reported by Martinez et al. (22). Data on comorbidities were collected from the patients' medical records and quantified according to the Charlson index (23).

\section{Statistical analysis}

All data were analyzed using the SigmaStat 3.2 (Inc., USA) software. Means \pm SD or median interquartile range $(25-75 \%)$ was used depending on the data distribution. When comparing excluded patients to those who completed the study, the unpaired $t$-test was used for continuous variables and the Mann-Whitney test for ordinal variables. The paired $t$-test or Wilcoxon test was applied to compare the characteristics at baseline to those observed after 3 years. Chi-square tests were used to evaluate qualitative variables with a frequency higher than five. The level of significance was set at $\mathrm{P}<0.05$.

\section{Results}

Of the 133 patients initially evaluated, 38 were excluded from the final analyses; 15 patients died and 23 dropped out. The causes of deaths were pulmonary complications resulting from COPD in 8 patients, cardiovascular disease in 5 patients, splenic abscess/septic shock in one patient, and colon cancer in one patient. Dropouts were due to one of the following reasons: unable to contact $(N=9)$, declined to participate $(\mathrm{N}=12)$, inability to perform the 6MWD $(\mathrm{N}=$ $1)$, and clinical worsening of congestive heart failure $(\mathrm{N}=1)$. Thus, 95 patients were monitored for 3 years. Comparisons of the dropouts and of the patients who died versus those completing the study did not show significant differences at baseline (Table 2).

At baseline, the mean age of the 95 patients studied (66\% men) was $64 \pm 9$ years and smoking exposure was $54 \pm 28$ pack-years; 32 patients (33\%) were smokers, and 8 patients $(25 \%)$ stopped smoking during follow-up. As to severity, 17 patients (18\%) presented mild, 39\% moderate, $19 \%$ severe, and $24 \%$ a very severe COPD. There was no difference in the proportion of patients within each disease severity category at baseline and after 3 years $(P$ $=0.865$ ).

The comparison of patient characteristics at baseline and after 3 years is shown in Table 3 . There was no significant change in $\mathrm{FEV}_{1}$ or FVC values after the use of a bronchodilator, expressed as \% of predicted values, or in body composition. The $\mathrm{FEV}_{1}$ value, in liters, worsened significantly, with a mean rate of decline of $26 \mathrm{~mL} / \mathrm{year}$ $(95 \% \mathrm{Cl}=15-38 \mathrm{~mL} /$ year; $\mathrm{P}=0.001)$. The FVC value, in liters, also worsened significantly during the study period. There were significant deteriorations of $\mathrm{SpO}_{2}, \mathrm{MRC}$, and BODE index compared to baseline. Twenty-seven patients presented weight loss (>1 unit BMI), $52 \%$ of whom were in severe to very severe stages of the disease.

Table 2. Comparison of the characteristics of patients who died or dropped out versus those who completed the study.

\begin{tabular}{|c|c|c|}
\hline Variables & $\begin{array}{l}\text { Patients who died or } \\
\text { dropped out }(\mathrm{N}=38)\end{array}$ & $\begin{array}{l}\text { Patients who completed the } \\
\text { study }(\mathrm{N}=95)\end{array}$ \\
\hline Gender F/M (N) & $9 / 29$ & $32 / 63$ \\
\hline Age (years) & $65(58-74)$ & $64(59-71)$ \\
\hline $\mathrm{FEV}_{1}(\%)$ & $61(36-77)$ & $54(41-73)$ \\
\hline FVC (\%) & $96(69-114)$ & $86(74-104)$ \\
\hline $\mathrm{FEV}_{1} / \mathrm{FVC}$ & $52(38-62)$ & $53(43-63)$ \\
\hline BMI $\left(\mathrm{kg} / \mathrm{m}^{2}\right)$ & $24(21-27)$ & $25(22-29)$ \\
\hline 6MWD (m) & $426 \pm 103$ & $438 \pm 85$ \\
\hline MRC scale (score) & $1(1-2)$ & $1(1-2)$ \\
\hline $\mathrm{SpO}_{2}(\%)$ & 95 (93-96) & $94(92-96)$ \\
\hline BODE index & $2(0-3)$ & $2(1-4)$ \\
\hline Charlson index & $3(3-4)$ & $3(3-4)$ \\
\hline
\end{tabular}

Data are reported as means \pm SD or as median $(25-75 \%$ interquartile range). $\mathrm{F} / \mathrm{M}=$ female $/$ male; $F E V_{1}=$ forced expiratory volume in the first second ( $\%$ of predicted); FVC = forced vital capacity ( $\%$ of predicted); $\mathrm{BMI}=$ body mass index; 6MWD: 6 -min walking distance; $\mathrm{MRC}=$ Medical Research Council; $\mathrm{SpO}_{2}=$ pulse oximetry; BODE index = BMI/airflow obstruction/dyspnea/ exercise capacity. There was no significant difference between groups (unpaired $t$-test or Mann-Whitney test). 
According to the criteria set for the study, 41 patients (43\%) showed stability of BODE index, 37 (39\%) worsened (increase $\geq 1$ point) and $17(18 \%)$ presented improvement $\geq 1$ point. Of the 37 patients who deteriorated, 25 (67\%)

Table 3. Characteristics of patients with chronic obstructive pulmonary disease followed up over a 3-year period.

\begin{tabular}{lcc}
\hline Variables & $\begin{array}{c}\text { Initial assessment } \\
(\mathrm{N}=95)\end{array}$ & $\begin{array}{c}\text { Final assessment } \\
(\mathrm{N}=95)\end{array}$ \\
\hline $\mathrm{FEV}_{1}(\%)$ & $54(41-73)$ & $54(40-70)$ \\
$\mathrm{FEV}_{1}(\mathrm{~L})$ & $1.25(0.96-1.72)$ & $1.26(0.88-1.60)^{*}$ \\
$\mathrm{FVC}(\%)$ & $86(74-104)$ & $87(71-106)$ \\
$\mathrm{FVC}(\mathrm{L})$ & $2.6(2.2-3.0)$ & $2.4(1.9-3.0)^{*}$ \\
$\mathrm{FEV} / \mathrm{FVC}$ & $52 \pm 12$ & $51 \pm 10$ \\
$\mathrm{BMI}\left(\mathrm{kg} / \mathrm{m}^{2}\right)$ & $25(22-29)$ & $25(22-29)$ \\
$\mathrm{FFM}(\mathrm{kg})$ & $42(38-47)$ & $41(37-47)$ \\
Depleted/not depleted $(\mathrm{N})_{\mathrm{SpO}}(\%)$ & $38 / 57$ & $41 / 54$ \\
$\mathrm{MRC} \mathrm{scale} \mathrm{(score)}_{\mathrm{BODE} \text { index (score) }}$ & $94(92-96)$ & $93(90-95)^{*}$ \\
$6 \mathrm{MWD}(\mathrm{m})$ & $2.2 \pm 1.8$ & $2(1-3)^{*}$ \\
\hline
\end{tabular}

Data are reported as means \pm SD or as median $(25-75 \%$ interquartile range). $\mathrm{FEV}_{1}=$ forced expiratory volume in the first second (\% of predicted); FVC = forced vital capacity ( $\%$ of predicted); $\mathrm{BMI}=$ body mass index; FFM = fat-free mass; Depleted/not depleted $=$ patients with lean body mass depletion/patients without lean body mass depletion; $\mathrm{SpO}_{2}=$ pulse oximetry; $\mathrm{MRC}=$ Medical Research Council; BODE index = BMI/airflow obstruction/dyspnea/exercise capacity. ${ }^{*} \mathrm{P}<0.05$, final assessment compared to initial assessment (paired $t$-test or Wilcoxon test). presented severe or very severe COPD. As to the variables that compose the BODE index, in 35 patients the increase in the index was due to an increase in the MRC, the 6MWD decreased in 6 patients while 7 showed concomitant changes.

The 6MWD decreased significantly after 3 years. According to the values proposed by different investigators $(19,20), 31$ patients $(32 \%)$ presented clinically significant worsening ( $\geq 54 \mathrm{~m}$ ) and in 36 patients $(38 \%)$ the decrease in 6 MWD was $\geq 35 \mathrm{~m}$. The proportion of patients with a minimum clinically significant decline ranged from 50 to $58 \%$ among patients with severe or very severe disease. The Charlson index increased significantly during the study period [3 (3-4) vs 4 (3-5); $P=0.009$ ]. In 20 patients, the increase was attributable only to the change in patient age.

Health status presented a significant increase in the activity domain score $(52 \pm 21$ vs $60 \pm 22 \%$; $P<0.001)$ and SGRQ total score (42 \pm 19 vs $44 \pm 19 \%$; $P=0.041$; Figure 1). Fifty-one percent of the patients presented clinically significant worsening ( $\geq 4 \%$ ) in SGRQ total score while $58 \%$ showed deterioration in the activity domain.

\section{Discussion}

We have performed a 3-year follow-up of respiratory and systemic manifestations of COPD patients. Decreased exercise tolerance and increased dyspnea sensation may occur despite only minor modifications in airway obstruction and body composition. Furthermore, the multidimensional BODE index, which includes various aspects of the disease, showed significant worsening during the 3-year study pe-

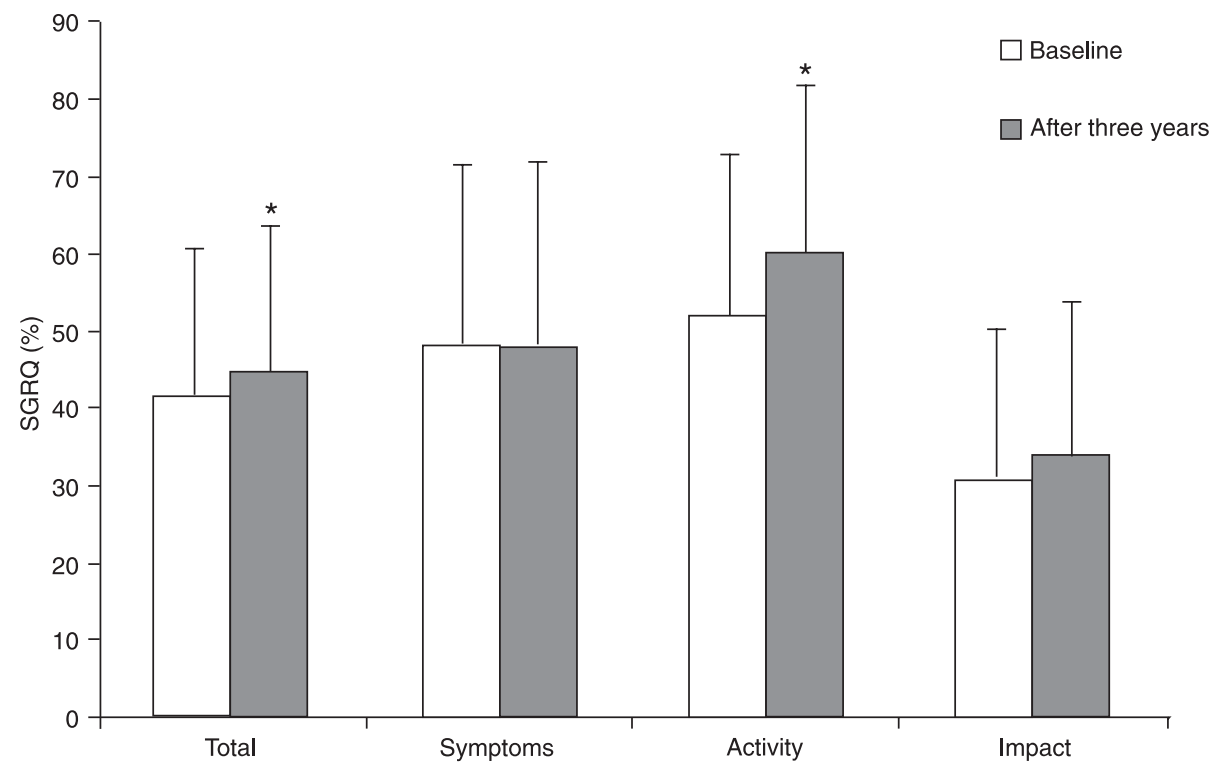

Figure 1. Mean SGRQ (Saint George's Respiratory Questionnaire) domains at baseline and after 3 years. ${ }^{*} P<0.05$, baseline values compared to values observed after 3 years (paired $t$-test or Wilcoxon test). 
riod. Taken together, these data agree with international studies and support the concept that monitoring of patients with COPD should include other indicators in addition to those related to airway obstruction.

$\mathrm{FEV}_{1}$ is a simple and valid measurement of airflow obstruction and is often used to stage disease severity in COPD (1). In our study, the value of $F E V_{1}$, expressed as percentage of predicted values, showed no significant change during the 3-year follow-up, while the value in liters decreased significantly. The mean rate of decline in $\mathrm{FEV}_{1}$ was $26 \mathrm{~mL} /$ year, and only 22 patients (23\%) presented changes greater than $200 \mathrm{~mL}$ and $12 \%$ within a 3-year period. These results are consistent with those reported by Casanova et al. (8), who showed that $\mathrm{FEV}_{1}$ values, in liters, declined significantly over $5 \mathrm{~s}$, with a $23 \mathrm{~mL} /$ year mean rate of decline.

Despite minor modifications in airway obstruction and body composition, the exercise tolerance decreased and dyspnea sensation increased during the study period. The deterioration in exercise tolerance was clinically significant in $32 \%(\geq 54 \mathrm{~m})$ to $38 \%(\geq 35 \mathrm{~m})$ of the subjects and the proportion of patients with these declines was very similar among the different categories of disease severity. Another prospective study evaluated COPD patients with a wide range of airflow obstruction during a 5-year period. They also showed an annual decline of the 6MWD; however, in contrast to our findings, the 54-m decrease was really significant only in patients whose $\mathrm{FEV}_{1}$ was less than $50 \%$ of predicted values (8).

Another symptom related to COPD severity that worsened significantly during follow-up was the dyspnea assessed by MRC. In 76 COPD patients monitored for 2 years, Mahler et al. (5) found that, despite improvement in lung function, dyspnea scores assessed by the Transition Dyspnea Index (TDI) increased significantly. Other studies have also shown uncoupling between dyspnea perception and airway obstruction over time $(6,7)$. Lareau et al. (6) showed a significant decrease in mean $\mathrm{FEV}_{1}$ values $(\%$ predicted) without change in dyspnea scores after 5 years of follow-up of 34 COPD patients. Our results agree with Oga et al. (7) who showed a significant worsening of dyspnea within 5 years of follow-up and a weak correlation between changes in dyspnea and the decline in pulmonary function. In summary, our data support the concept that changes in the dyspnea sensation occur independently of alterations in airway obstruction assessed by $\mathrm{FEV}_{1}$. Therefore, assessment of dyspnea in the monitoring of COPD is crucial and should be undertaken independently of spirometry monitoring according to the recommendations of Brazilian and international guidelines $(1,9)$. These data also support the view of the importance of inclusion of pulmonary rehabilitation in the management of COPD patients since this treatment modality has a beneficial effect on dyspnea sensation and exercise tolerance (24).

Our results revealed no significant change in body composition after the 3-year period. Prescott et al. (25) evaluated 1612 patients with COPD (736 women and 876 men) and reported that the mean weight loss was greater in patients with severe and very severe degrees compared to those with mild to moderate stages of the disease after 5 years. The proportion of patients who had a weight loss (>1 unit BMI) was $30 \%$ in patients with severe COPD. Our results showed that 27 patients $(28 \%)$ presented weight loss (>1 unit $\mathrm{BMI}$ ), and $52 \%$ of them presented severe to very severe COPD. We also showed a prevalence of malnutrition $\left(\mathrm{BMI}<21 \mathrm{~kg} / \mathrm{m}^{2}\right)$ at baseline $(20 \%)$ similar to that previously reported in studies conducted in Brazil and reported in the international literature (26-28). The prevalence of FFM depletion at baseline was on average $40 \%$, with no difference between classes of disease severity. In the literature, the prevalence of FFM depletion varies from $18(27,28)$ to $52 \%(29)$ depending on the patient group, illness severity and depletion criterion employed.

The BODE index increased significantly during the study period, supporting the importance of multidimensional assessment in monitoring COPD patients. The main variable determining the increase in BODE index was dyspnea, assessed by MRC. In our study, despite the significant decrease in mean 6MWD results, the proportion of patients who had an increased BODE index due to changes in the 6MWD was low, since the mean 6MWD values were greater than $365 \mathrm{~m}$. These results are supported by the fact that the time spent walking in daily life in the Brazilian COPD group (56 $\pm 32 \mathrm{~min} /$ day) was markedly longer than that observed in the Austrian sample (40 $\pm 36 \mathrm{~min} /$ day $)$ from the study of Pitta et al. (30).

In the present study, in addition to evaluating the components of the BODE index we investigated the health status of the patients. During follow-up we observed a significant worsening in the activity domain and SGRQ total score, in agreement with data reported by Oga et al. (7), who showed a deterioration of health status as indicated by an increased activity and impact domain, and SGRQ total score after a 5-year period. The increase in dyspnea sensation may partially explain these results since this symptom is an important determinant of health status $(7,31)$. These results suggest that health status scores should be included as part of a comprehensive assessment to evaluate disease progression.

The present study has some limitations. First, we excluded patients with comorbidities; therefore, many patients seen in clinical practice may not have been well represented in our study. Although the total sample size was sufficient to draw conclusion about group evolution, the power of the study was not ideal for subgroup analyses according to disease severity, which were not performed. Since the sample size of the patients who stopped smoking during follow-up was very small, the influence of smoking cessation was not evaluated. In our study, the proportion of patients who presented health status deterioration was 
greater than the proportion of those presenting deterioration in 6MWD and BODE index. In addition to the increase in dyspnea sensation, psychological factors may also have influenced these results (32). However, these evaluations were not included in our design. We also recognize that comparisons with previous studies $(7,8)$ may indicate some discrepancies due to differences in follow-up time; however, for most of the outcomes our findings were similar to those previously described. In addition, data about exacerbations during follow-up were evaluated for the entire group and have been presented in a previous publication (33). However, their influence on patient follow-up was not evaluated in the present study.

\section{References}

1. Fabbri LM, Luppi F, Beghe B, Rabe KF. Update in chronic obstructive pulmonary disease 2005. Am J Respir Crit Care Med 2006; 173: 1056-1065.

2. Mahler DA, Weinberg DH, Wells CK, Feinstein AR. The measurement of dyspnea. Contents, interobserver agreement, and physiologic correlates of two new clinical indexes. Chest 1984; 85: 751-758.

3. Jones PW, Quirk FH, Baveystock CM, Littlejohns P. A selfcomplete measure of health status for chronic airflow limitation. The St. George's Respiratory Questionnaire. Am Rev Respir Dis 1992; 145: 1321-1327.

4. O'Donnell DE, Lam M, Webb KA. Measurement of symptoms, lung hyperinflation, and endurance during exercise in chronic obstructive pulmonary disease. Am J Respir Crit Care Med 1998; 158: 1557-1565.

5. Mahler DA, Tomlinson D, Olmstead EM, Tosteson AN, O'Connor GT. Changes in dyspnea, health status, and lung function in chronic airway disease. Am J Respir Crit Care Med 1995; 151: 61-65.

6. Lareau SC, Meek PM, Press D, Anholm JD, Roos PJ. Dyspnea in patients with chronic obstructive pulmonary disease: does dyspnea worsen longitudinally in the presence of declining lung function? Heart Lung 1999; 28: 65-73.

7. Oga T, Nishimura K, Tsukino M, Sato S, Hajiro T, Mishima M. Longitudinal deteriorations in patient reported outcomes in patients with COPD. Respir Med 2007; 101: 146-153.

8. Casanova C, Cote CG, Marin JM, de Torres JP, AguirreJaime A, Mendez R, et al. The 6-min walking distance: longterm follow up in patients with COPD. Eur Respir J 2007; 29: 535-540.

9. Jardim JR, Oliveira JA, Nascimento O. II Consenso Brasileiro de DPOC. J Bras Pneumol 2004; 30: S1-S42.

10. Standardization of spirometry - 1987 update. Statement of the American Thoracic Society. Am Rev Respir Dis 1987; 136: 1285-1298.

11. Knudson RJ, Lebowitz MD, Holberg CJ, Burrows B. Changes in the normal maximal expiratory flow-volume curve with growth and aging. Am Rev Respir Dis 1983; 127: 725-734.

12. Kyle UG, Bosaeus I, De Lorenzo AD, Deurenberg P, Elia M, Gomez JM, et al. Bioelectrical impedance analysis - part I: review of principles and methods. Clin Nutr 2004; 23: 12261243.
The present study has shown that, regardless of the development of airway obstruction and body composition, there is worsening of other systemic manifestations of COPD over time. These findings in Brazilian patients with COPD agree with other studies that evaluated COPD patients and support the need for a more comprehensive assessment of the patient to better identify disease progression.

\section{Acknowledgments}

Research supported by FAPESP (\#04/00517-4). R. Ferrari was the recipient of a fellowship from FAPESP (\#2008/52667-0).

13. Kyle UG, Pichard C, Rochat T, Slosman DO, Fitting JW, Thiebaud D. New bioelectrical impedance formula for patients with respiratory insufficiency: comparison to dualenergy X-ray absorptiometry. Eur Respir J 1998; 12: 960966.

14. Schols AM, Broekhuizen R, Weling-Scheepers CA, Wouters EF. Body composition and mortality in chronic obstructive pulmonary disease. Am J Clin Nutr 2005; 82: 53-59.

15. Sousa TC, Jardim JR, Jones P. Validation of the Saint George Respiratory Questionnaire (SGRQ) in patients with chronic obstructive disease in Brazil. J Bras Pneumol 2000; 26: 119-125.

16. Schunemann HJ, Griffith L, Jaeschke R, Goldstein R, Stubbing $\mathrm{D}$, Guyatt $\mathrm{GH}$. Evaluation of the minimal important difference for the feeling thermometer and the St. George's Respiratory Questionnaire in patients with chronic airflow obstruction. J Clin Epidemiol 2003; 56: 1170-1176.

17. Kovelis D, Segretti NO, Probst VS, Lareau SC, Brunetto AF, Pitta F. Validation of the Modified Pulmonary Functional Status and Dyspnea Questionnaire and the Medical Research Council scale for use in Brazilian patients with chronic obstructive pulmonary disease. J Bras Pneumol 2008; 34: 1008-1018.

18. ATS statement: guidelines for the six-minute walk test. $A m$ J Respir Crit Care Med 2002; 166: 111-117.

19. Redelmeier DA, Bayoumi AM, Goldstein RS, Guyatt GH. Interpreting small differences in functional status: the Six Minute Walk test in chronic lung disease patients. Am J Respir Crit Care Med 1997; 155: 1278-1282.

20. Puhan MA, Mador MJ, Held U, Goldstein R, Guyatt GH, Schunemann HJ. Interpretation of treatment changes in 6-minute walk distance in patients with COPD. Eur Respir $J$ 2008; 32: 637-643.

21. Celli BR, Cote CG, Marin JM, Casanova C, Montes de OM, Mendez RA, et al. The body-mass index, airflow obstruction, dyspnea, and exercise capacity index in chronic obstructive pulmonary disease. N Engl J Med 2004; 350: 1005-1012.

22. Martinez FJ, Han MK, Andrei AC, Wise R, Murray S, Curtis $\mathrm{JL}$, et al. Longitudinal change in the BODE index predicts mortality in severe emphysema. Am J Respir Crit Care Med 2008; 178: 491-499.

23. Charlson M, Szatrowski TP, Peterson J, Gold J. Validation 
of a combined comorbidity index. J Clin Epidemiol 1994; 47: 1245-1251.

24. Ries AL, Bauldoff GS, Carlin BW, Casaburi R, Emery CF, Mahler DA, et al. Pulmonary Rehabilitation: Joint ACCP/ AACVPR Evidence-Based Clinical Practice Guidelines. Chest 2007; 131: 4S-42S.

25. Prescott E, Almdal T, Mikkelsen KL, Tofteng CL, Vestbo J, Lange P. Prognostic value of weight change in chronic obstructive pulmonary disease: results from the Copenhagen City Heart Study. Eur Respir J 2002; 20: 539-544.

26. Dourado VZ, Antunes LC, Tanni SE, de Paiva SA, Padovani $\mathrm{CR}$, Godoy I. Relationship of upper-limb and thoracic muscle strength to 6-min walk distance in COPD patients. Chest 2006; 129: 551-557.

27. Schols AM, Soeters PB, Dingemans AM, Mostert R, Frantzen PJ, Wouters EF. Prevalence and characteristics of nutritional depletion in patients with stable COPD eligible for pulmonary rehabilitation. Am Rev Respir Dis 1993; 147: 1151-1156.

28. Engelen MP, Schols AM, Baken WC, Wesseling GJ, Wouters EF. Nutritional depletion in relation to respiratory and peripheral skeletal muscle function in out-patients with COPD. Eur
Respir J 1994; 7: 1793-1797.

29. Steuten LM, Creutzberg EC, Vrijhoef HJ, Wouters EF. COPD as a multicomponent disease: inventory of dyspnoea, underweight, obesity and fat free mass depletion in primary care. Prim Care Respir J 2006; 15: 84-91.

30. Pitta F, Breyer MK, Hernandes NA, Teixeira D, Sant'Anna $T J$, Fontana $A D$, et al. Comparison of daily physical activity between COPD patients from Central Europe and South America. Respir Med 2009; 103: 421-426.

31. Schlecht NF, Schwartzman K, Bourbeau J. Dyspnea as clinical indicator in patients with chronic obstructive pulmonary disease. Chron Respir Dis 2005; 2: 183-191.

32. Hajiro T, Nishimura K, Tsukino M, Ikeda A, Koyama H, Izumi T. Comparison of discriminative properties among diseasespecific questionnaires for measuring health-related quality of life in patients with chronic obstructive pulmonary disease. Am J Respir Crit Care Med 1998; 157: 785-790.

33. Faganello MM, Tanni SE, Sanchez FF, Pelegrino NR, Lucheta PA, Godoy I. BODE index and GOLD staging as predictors of 1-year exacerbation risk in chronic obstructive pulmonary disease. Am J Med Sci 2010; 339: 10-14. 